\title{
ÁGUA NOSSA DE CADA DIA: O DISCURSO PERSUASIVO DOS ATRIBUTOS VISUAIS NOS INFOGRÁFICOS
}

\author{
Daniel Moura Nogueira \\ PUC-Rio \\ daniel.m.nogueira@gmail.com \\ Frederico Braida Rodrigues de Paula \\ UFJF \\ frederico.braida@ufjf.edu.br \\ Vera Lucia Moreira dos Santos Nojima \\ PUC-Rio \\ nojima@puc-rio.br
}

Resumo: Os infográficos, um dos produtos do Design da Informação, podem ser usados como ferramenta de comunicação, com o objetivo de transmitir informações de modo sintético, rápido e atraente, por meio de representações visuais diagramáticas. Este artigo aborda o tema do discurso persuasivo nos infográficos. Trata-se de uma análise dos atributos visuais dos gráficos e infográficos, sob o ponto de vista da retórica visual. Os aportes teóricos encontram-se na proposta de uma Retórica do Design, de Almeida Junior, fundamentada na Nova Retórica, de Chaïm Perelman e Lucie Olbrechts-Tyteca, e nas investigações sobre a Percepção Visual voltada à visualização de dados, de Colin Ware e Stephen Few. Como caso exemplar, foi elaborada uma análise dos aspectos gráficos e retóricos do infográfico "Água nossa de cada dia", da seção Jornais da 6ạ Mostra Nacional de Infografia de 2012, o Infolide. Ao final, evidencia-se a intensa presença dos recursos retórico-visuais e das ferramentas de persuasão no desenvolvimento de infográficos, os quais são utilizados pelos designers para uma comunicação efetiva de suas mensagens e para capturar, convincentemente, a atenção dos receptores.

Palavras-chave: Infográfico, retórica visual, persuasão, atributos visuais.

Abstract: Infographics, one of the products of the Information Design, can be used as a communication tool with the purpose of transmitting information in a syntetic way, fast and attractive through diagrammatic visual representations. This article discusses the persuasive speech topic in infographics. This is an analysis of the visual attributes of the charts and infographics from the point of view of visual rhetoric. The theoretical references of the research are the proposal of a Rhetoric of Design, by Almeida Junior, based on the New Rhetoric of Chaïm Perelman and Lucie Olbrechts-Tyteca, and the investigations on Visual Perception oriented to 
data visualization, in surveys of Colin Ware and Stephen Few. As a special case, was made an analysis of graphics and rhetorical aspects of the infographic "our water every day," from the Newspaper Infographics section of the 6th National Exhibition of 2012, Infolide. Finally, it highlights the intense presence of rhetorical-visual resources and tools of persuasion in the development of infographics, which are used by designers for effective communication of their messages and to capture convincingly the attention of recipients.

Keywords: Infographic, visual rhetoric, persuasion, visual attributes.

\section{INTRODUÇÃO}

Os infográficos podem se apresentar em diversos suportes e em diferentes mídias, tais como jornais, revistas, livros, manuais técnicos, textos acadêmicos, propagandas, dentre outros e são usados "sempre que se pretende explicar algo, de uma forma clara e, sobretudo, quando só o texto não é suficiente para fazê-lo de maneira objetiva" (TEIXEIRA, 2007, p. 112 apud MÓDOLO, 2008, p.18). Os infográficos, recorrentemente, estão presentes em tarefas corriqueiras do nosso cotidiano, tais como: no momento de decidir que roupa usar, ao ver um gráfico sobre a previsão climática; na escolha da trajetória a ser seguida, a partir de um mapa com o boletim do trânsito; na compra de alimentos "saudáveis", segundo um gráfico que indique a quantidade de carboidratos ideal para a saúde. Ou seja, rotineiramente, as escolhas que influenciam o cotidiano, comportamento, sentimentos e relações sociais derivam de análises de uma miríade de gráficos.

Segundo Kristeva (1974, p.9), "o homem moderno está mergulhado na linguagem, vive na fala, é assaltado por milhares de signos, a ponto de já quase só ter uma existência de emissor e receptor". A linguagem do design gráfico é um sistema intuitivo e se completa com a experiência pessoal do leitor. Nessa linguagem, se inclui os produtos do design da informação, tais como os infográficos.

Ainda não é possível lidar facilmente com o excesso do volume de dados gerados diariamente. Assim, os gráficos nos auxiliam a analisar, interpretar e compreender os dados de uma forma sintética e direcionada à capacidade cognitiva do ser humano. De acordo com Few (2009, p.7), uma boa análise de dados ajuda a compreender o que está acontecendo em um determinado momento e a melhor prever o que pode acontecer sob determinadas circunstâncias no futuro, de forma que se possa criar oportunidades e prevenir problemas. Gráficos e infográficos nos ajudam a pensar e, também, auxiliam na tarefa de tomar decisões. No entanto, essas decisões partem de informações que são transmitidas através do discurso presente em um gráfico apresentado em um suporte, seja ele uma revista, uma embalagem, uma apresentação corporativa etc. Conforme Bonsiepe (1999, p.167-172 apud LIMA, 2009, p.42), não há discurso neutro, não há informação sem retórica, ou seja, recursos linguísticos presentes nas visualizações levam o leitor a concordar com uma determinada opinião que Ihe foi apresentada. Não há uma neutralidade, seja qual meio for.

Designers e jornalistas visuais ao redor do mundo aprenderam a otimizar os infográficos por meio da prática ao longo das décadas. Jacques Bertin (1918-2010) 
trouxe a primeira fundamentação teórica relevante ao campo, com o livro Semiologie graphique, em $1967^{1}$. O uso racionalizado de atributos visuais como contraste, cores, texturas, direções e volumes tornaram as visualizações de dados mais efetivas e evidentes. Uma maior compreensão da cognição humana fez com que a possibilidade de interpretação dos gráficos fosse potencializada, reduzindo os ruídos. A aplicação desses conhecimentos tem favorecido a construção de um discurso visual mais eloquente, dado que as relações entre os elementos visuais em um gráfico irão definir como as informações nele se apresentarão.

Portanto, o principal objetivo deste artigo é apresentar um caminho possível para a análise dos atributos visuais dos gráficos e infográficos, sob o ponto de vista da retórica visual, a fim de contribuir para a formação de designers gráficos, seja nos processos de análise de gráficos já existentes ou de projeto de infográficos. 0 referencial teórico da abordagem apresentada neste artigo fundamenta-se nas pesquisas sobre a Retórica do Design Gráfico, proposta por Almeida Junior (2009), com bases no Tratado da argumentação, a Nova Retórica, de Perelman e Olbrechts-Tyteca (2005), e, também, nas pesquisas no campo da percepção visual, compiladas por Ware (2004) e Few (2009).

\section{QUESTÕES SOBRE A PERSUASÃO}

No âmbito da infografia impressa, o papel do designer é transmitir a mensagem gerada pelo jornalista da melhor forma possível - de acordo com a sua capacidade intelectual, técnica e tempo disponível. Conforme Cairo (2008, p.53), o designer não é responsável por nortear o discurso editorial, escolher a mensagem ideológica do veículo ou da pauta; ele é responsável por traduzi-la ao leitor, visualmente, de forma efetiva, construindo uma nova narrativa. O design não é o único meio de persuasão disponível dos meios de comunicação, é mais um caminho, bem como o é um de seus produtos: o infográfico. Ou seja, para uma mesma pauta, com os mesmos dados, é possível contar uma "história" de formas diferentes. A narrativa escolhida conduz um leitor a interpretações distintas sobre um determinado assunto, dependendo de como foi desenvolvida e apresentada (visual e textualmente). Se há a possibilidade de interpretar, por exemplo, A ou B, a partir de uma visualização de dados, a escolha por um dos caminhos não parte do designer, mas do jornalista ou editor responsável. 0 papel do designer será transmitir a mensagem de forma compreensível (e persuasiva), levando o leitor a se convencer a partir do caminho apresentado, visando a sua adesão ao discurso proposto.

Nos anos de 1920, Otto Neurath propôs o conceito de "transformador", ou seja, o designer de informação seria um "transformador da informação", um profissional que reinterpreta as informações, transformando-as para adequá-las a diferentes públicos. Para Neurath (1980), os designers seriam intermediários entre historiadores, economistas, matemáticos e o seu público-alvo (WILDBUR e BURKE, 1998, p.7). De forma análoga, o designer responsável pela elaboração de um infográfico é um profissional que atua como projetista de um discurso visual, que fará a transição do discurso editorial ao leitor. Ele tem o papel de construir significados nas mensagens que serão representadas pelos dados em diagramas esquemáticos, conforme Souza Leite (1997, p.5), atuando como intermediador no processo

\footnotetext{
${ }^{1}$ Ver Bertin (1983).
} 
comunicacional. O designer tem a capacidade de "trafegar em um sistema complexo de discursos interagentes, onde a noção de interdiscursividade se faz absolutamente necessária" (SOUZA LEITE, 1997, p.5). As escolhas acerca das representações visuais, seus atributos, disposições e como se dará a narrativa dependem da sua capacidade de traduzir ao leitor a mensagem jornalística (em seus diversos temas), por meio de novas construções simbólicas visuais advindas de uma vasta gama de fontes, tais como dados estatísticos, textos, mapas e imagens.

Sobre o processo de construção de significados em que o designer se insere, Almeida Junior e Nojima (2010, p.15) comenta:

O sucesso da ação do designer está diretamente vinculado à materialização de suas ideias em produtos que, pelas possibilidades de uso, geram significação. Essa manifestação semiótica confere a comunicabilidade exigida e desejada à construção dos significados e, consequentemente, à apreensão dos efeitos que estes possam produzir. Nesse sentido, as modalidades produtivas do Design Gráfico são consolidadas pela manipulação de imagens verbais e não verbais. [...].

Portanto, faz-se necessário compreender o papel de construtor de um discurso em uma linguagem visual, observando-se como a retórica se manifesta na esfera de atuação do designer de informação. Sendo a retórica a "arte da persuasão", ela disponibiliza ferramentas e recursos que o designer pode usar no momento da construção do discurso de suas mensagens. Bonsiepe (1999, p.167-172 apud LIMA, 2009, p.42) afirma que a informação sem retórica é uma ilusão, em uma crítica à ideia da possibilidade de neutralidade na informação. A "retórica pode ser caracterizada como um conjunto de técnicas empíricas sedutoras utilizadas para influenciar as emoções e sentimentos dos destinatários da mensagem" (BONSIEPE, 2011, p.115). A partir de abordagens de uma retórica visual em peças publicitárias, Bonsiepe (2011) evidencia a importância da persuasão nas mensagens, elege-a como um dos objetivos principais do design publicitário. Entretanto, Bonsiepe (2011, p.115) reitera que "a retórica é um dos campos menos pesquisados do design, embora o designer enfrente inevitavelmente esse fenômeno no seu trabalho projetual cotidiano".

\subsection{Retórica do Design Gráfico}

O campo da argumentação é o do provável, do plausível, distante do mundo da exatidão cartesiana, do cálculo matemático, da demonstração lógica. A linguagem natural faz com que a argumentação seja, por consequência, ambígua e inexata. $A$ ambiguidade é inerente a todas as linguagens, as quais são influenciadas por ideologias, ou seja, se utilizam e sofrem a ação de efeitos retóricos. O Design Gráfico não foge a essa estrutura, uma vez que pode ser caracterizado como uma linguagem resultante de prática projetual com bases na manipulação de imagens. O Design Gráfico é uma especialidade do Design em que se desenvolvem projetos, cuja mensagem se pretende persuasiva, apresentando efeitos de uma retórica própria: a Retórica do Design Gráfico (ALMEIDA JUNIOR; NOJIMA, 2010). Segundo Almeida Junior (2010, p.76), "enquanto linguagem [o Design Gráfico], nunca é neutro, resguarda sempre uma ambiguidade e, ideologicamente norteado, traz uma argumentação e detém uma retórica específica". E, ainda, "a Retórica do Design Gráfico se constitui 
para alcançar a persuasão, determinada pela identificação do público; pela proposição da finalidade do discurso; pelo estabelecimento do gênero; pelos argumentos a serem empregados" (ALMEIDA JUNIOR, 2010, p.77).

Sendo o Design da Informação uma área do Design [Gráfico], ressalta-se a inclusão do mesmo no fato de "usar e sofrer efeito" de uma retoricidade, portanto, da Retórica do Design Gráfico. Desta forma, mostra-se relevante o aprofundamento dos conhecimentos acerca da Retórica para ampliar o ferramental persuasivo dos produtos do Design da Informação, tais como infográficos, visualizações de dados, dentre outros.

\subsection{Tratado da Argumentação: a Nova Retórica}

A Nova Retórica, proposta por Chaïm Perelman e Lucie Olbrechts-Tyteca, propiciou um ambiente teórico conceitual renovador de suma importância aos princípios da Retórica Clássica. A fundamentação da obra de Almeida Junior (2009) fornece uma compreensão acerca do Tratado da Argumentação, com a exposição das principais mudanças ou rupturas em relação à Retórica clássica:

A teoria de Perelman desenvolve uma Retórica renovada, voltada à argumentação e aos julgamentos de valor. É o discurso de uma racionalidade que já não pode evitar os debates e defende o pluralismo, a democracia e a liberdade intelectual ilimitada. [...] Componente da linguagem, instrumento ideológico e defensora de teses, a fundamentação do conceito renovado de Retórica propõe a apresentação de provas a serem postas por alguém para o julgamento de outrem (ALMEIDA JUNIOR, 2010, p.21).

A proposta de Perelman rompe com o raciocínio matemático cartesiano tradicional ocidental, com a razão positivista que tornava irracional a imaginação e a intuição, refutando a retórica, que aceitava apenas a existência de uma verdade absoluta. Na Nova Retórica, a racionalidade baseia-se no pluralismo e na liberdade humana. $O$ "irracional" é o pensamento lógico formal, que restringe a possibilidade de se aceitar o múltiplo e o provável. A Nova Retórica valoriza a "lógica dos julgamentos de valor", a argumentação baseada no plausível, no potencialmente possível, onde a exatidão matemática não define uma resposta de forma precisa. Ela visa a um lugar de equilíbrio entre a demonstração científica e a arbitrariedade das crenças, que leve em consideração os problemas humanos. Não há uma exigência pelo processo de demonstração da lógica formal e se aceita a argumentação como ferramenta válida.

Essas questões devem ser levadas em consideração durante a elaboração de um infográfico, por exemplo. A forma como a narrativa será estabelecida, como se dará o discurso com leitor, como os elementos serão apresentados ao "auditório", ou seja, como a manipulação dos atributos visuais (cores, texturas, formas etc.) servirá ao propósito de transmitir uma determinada mensagem, devem ser atentamente elaborados pelo designer gráfico.

\section{ATRIBUTOS VISUAIS}

Para manipular o que atrairá a atenção do olhar em um infográfico, é importante conhecer quais características se destacam no campo visual do receptor. A 
psicóloga Anne Treismann ${ }^{2}$ foi pioneira na condução de experimentos e estudos sistemáticos sobre o funcionamento e identificação de padrões simples no sistema visual humano. Esses testes, apesar de terem contribuído para a compreensão dos primeiros estágios dos processos de percepção, foram questionados, já que os participantes sabiam a priori o que deveriam buscar nas imagens. Os experimentos foram repetidos posteriormente sem que os participantes soubessem o que procurar e, salvo exemplos mais óbvios, os alvos não foram percebidos (WARE, 2008, p.27). Pesquisas subsequentes revelaram que a intensidade da distinção de um objeto visual se dá principalmente na relação de contraste entre ele e os seus arredores, com o local onde está inserido. Isso quer dizer que um objeto se destaca com mais intensidade quando possui uma ou mais características visuais diferentes das dos demais elementos ao seu redor; e esse destaque é reforçado se os demais objetos são idênticos entre si ou possuem características visuais muito similares.

Por sua vez, Jacques Bertin, em 1967, foi o primeiro a desenvolver e a estabelecer um vocabulário básico das características visuais que podem ser exploradas no design de visualizações de dados abstratos. Ele abordou os princípios básicos de funcionamento da percepção visual e como usá-los em favor de representações visuais claras, eficientes e intuitivas, a partir da compreensão dos atributos visuais que chamam atenção do olhar humano. Sua contribuição foi tamanha, que, até hoje, pouco se alterou de suas nomenclaturas. Few $(2009$, p.15) cita que "todos aqueles que, desde Bertin, trabalharam em mapear propriedades visuais para os significados de dados abstratos, basearam-se em seu trabalho", destacando a relevância de Bertin para o Design de Informação.

Algumas características visuais são passíveis de serem processadas em níveis primários do sistema visual humano e permitem a percepção em apenas uma fixação do olhar. Outras características necessitam mais movimentos oculares e/ou processamento em nível intermediário para serem percebidas, tomando mais tempo e esforço do receptor. De acordo com Ware (2013, p.154), entre os principais atributos visuais que levam à distinção estão: cor (matiz, saturação e brilho), forma (largura, comprimento, tamanho, orientação, formato, curvatura, desfoque), posicionamento espacial (vertical e horizontal) e movimento.

Distinguir similaridades e diferenças entre os estímulos percebidos é importante para estabelecer o que deve ser identificado como parte de um todo e o que não deve. Como o cérebro busca constantemente padrões no campo visual, ele estabelece relações entre os elementos, dando-lhes grau de importância, classificações e hierarquias. Conforme Ware (2008, p.29), o efeito de destaque visual de um elemento tem relação direta com o contraste entre as características visuais dele e dos elementos ao seu redor. Assim, enquanto as semelhanças ajudam a agrupar elementos, as diferenças Ihes dão graus de importância heterogêneos. Tal como um objeto de maior dimensão é considerado mais importante que os de tamanhos menores em um conjunto, ou como uma palavra em negrito é percebida como destaque em um texto de fonte com peso regular. Essas relações serão reforçadas ou amenizadas com o uso dos atributos visuais, os valores a eles imputados e a distribuição espacial dos componentes no layout. O domínio dessas variáveis pode

\footnotetext{
${ }^{2}$ Conferir Treismann e Gormican (1988).
} 
permitir que o designer, com um mesmo conjunto de dados, possa construir significados diferentes, manipulando as relações entre os objetos e seus atributos.

\section{O INFOGRÁFICO “ÁGUA NOSSA DE CADA DIA”: UM CASO EXEMPLAR}

A fim de se observar, de forma prática, a presença de recursos da Retórica do Design Gráfico em infográficos na mídia impressa, foi adotado, como caso exemplar, o inforgráfico "Água nossa de cada dia", publicado no jornal O Dia, em 26 de junho de $2011^{3}$. O infográfico é do designer Gustavo Moore e foi apresentado na 6a Mostra de Infografia (INFOLIDE), realizada em São Paulo.

O infográfico aborda o assunto da escassez da água e apresenta, por meio de comparações visuais e numéricas, a quantidade de água que cada indivíduo gasta diariamente, a partir do uso direto e, principalmente, por meio do consumo de produtos que demandam grande volume de água em sua fabricação. $O$ infográfico tem por objetivo fazer o leitor tomar conhecimento da grande quantidade da água que consome, mas cujo volume não imagina.

Uma análise da composição, sob a ótica do design, identificando a distribuição e uso dos atributos visuais, de forma a hierarquizar os elementos no layout na página, bem como o cruzamento dos dados presentes nos textos verbais, considerando-se as características próprias do texto jornalístico, auxilia no esclarecimento sobre a participação do designer na elaboração do infográfico. A presença de figuras retóricas que alimentam a força argumentativa do discurso evidencia a importância da atuação do profissional de Design da Informação como um articulador de linguagem persuasiva, e não apenas como um mero construtor de gráficos esteticamente bem solucionados.

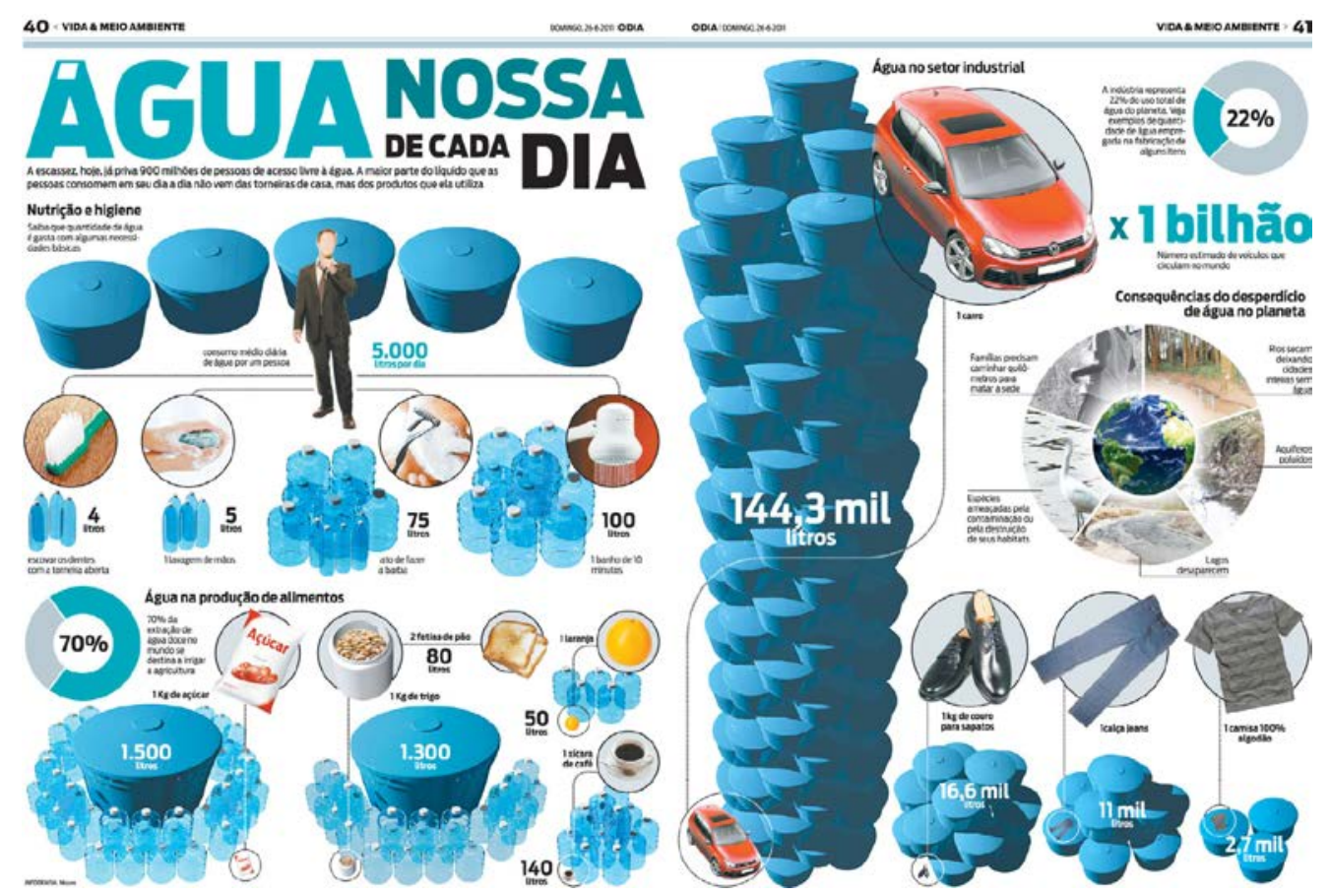

Figura 1 - Água nossa de cada dia. Jornal O Dia, 26 de junho de 2011. Design de Gustavo Moore. Fonte: INFOLIDE (2012, p.31).

\footnotetext{
${ }^{3}$ Para outros casos exemplares, ver Nogueira (2014).
} 
A seguir, apresentamos os passos da análise visual. Destaca-se que o roteiro utilizado não deve ser tomado como um método hermeticamente definido, mas como um caminho possível para futuras análises.

\subsection{Elementos do infográfico}

É importante identificar, em primeiro lugar, as características do infográfico selecionado. Esta abordagem visa a facilitar a compreensão sobre o posicionamento espacial e distribuição na composição das estruturas gráficas:

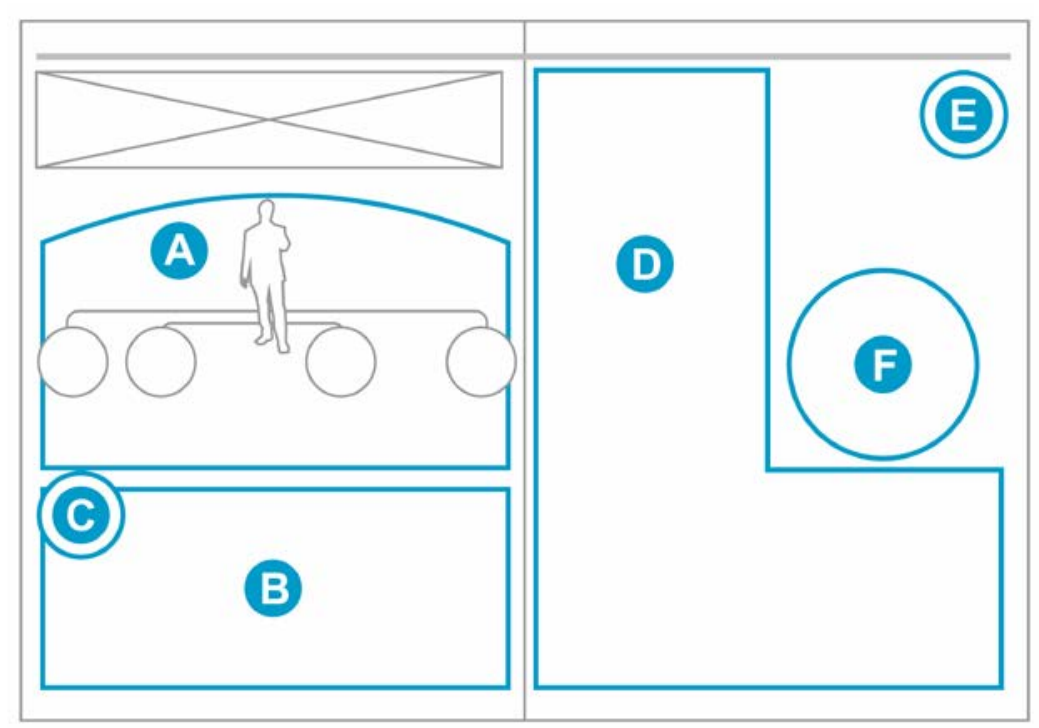

Figura 2 - Identificação de áreas com gráficos e blocos de informação do caso exemplar Fonte: Elaborado pelo autor, com base na pesquisa realizada.

Trata-se de um infográfico em página dupla, caracterizado pela pouca quantidade de texto, pelos gráficos de apoio e, principalmente, pela presença dominante do elemento central na página. Possui blocos de informação organizados em estruturas gráficas que dialogam entre si: (A) uma visualização do tipo organograma, que estabelece uma ordem hierárquica entre atividades cotidianas e um indivíduo de terno; (B) um gráfico com comparativo de volume de água na produção de alimentos disposto de forma semelhante a um gráfico de área, contando com o apoio de (C) um gráfico pizza, que aponta a fatia do gasto de água com alimentos em relação ao total; (D) um gráfico comparativo do volume de água no setor industrial, ordenado de forma similar a um gráfico de barras, que, no entanto, trata-se de um gráfico de área (por comparar os volumes através de imagens proporcionais), com o apoio de (E) um gráfico pizza, que indica a fatia da indústria no total. Os gráficos de área utilizam o recurso do "zoom" para facilitar a identificação dos elementos, aos quais o volume de água se relaciona. Há, ainda, (F) um diagrama ilustrado tipo artefoto similar a um gráfico pizza atrás de uma ilustração do planeta Terra, mostrando as possíveis consequências cataclísmicas do desperdício de água no planeta. 


\subsection{Impressões da composição gráfica}

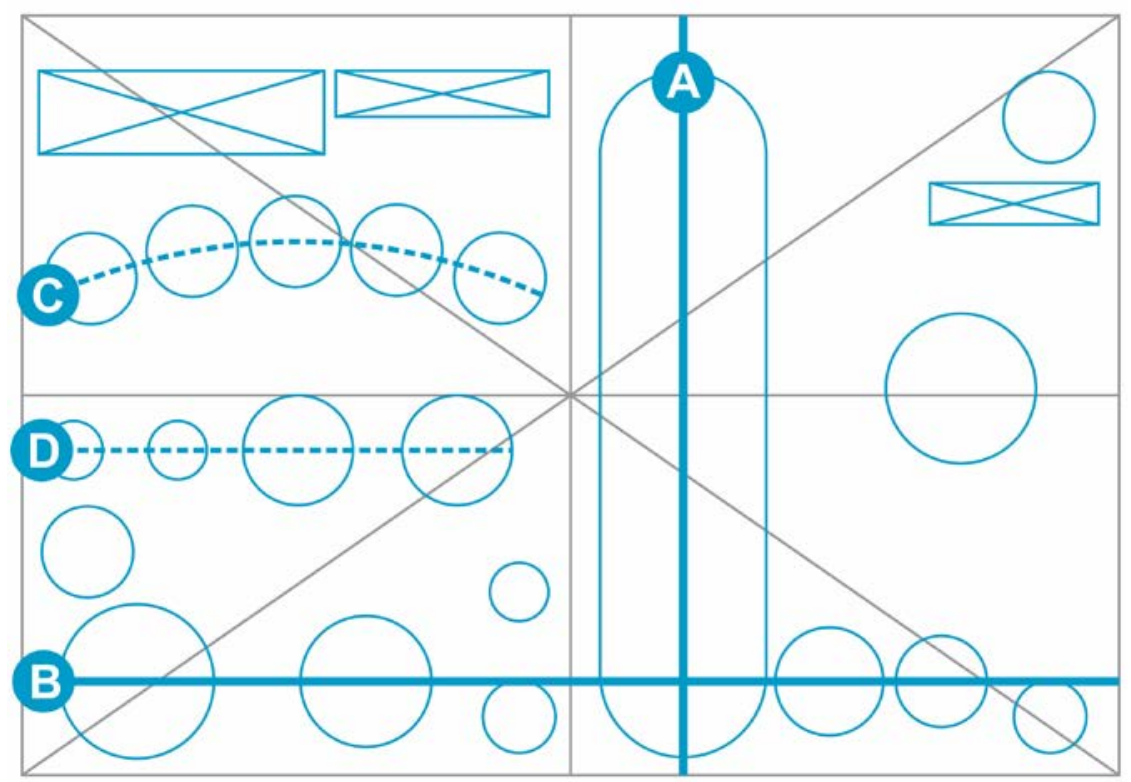

Figura 3 - Primeiras impressões sobre a composição gráfica do caso exemplar. Fonte: Elaborado pelo autor, com base na pesquisa realizada.

Em um nível de processamento básico da percepção, nota-se uma composição pautada pela presença de diversos elementos gráficos, predominantemente azuis, espalhados de forma, a princípio, desordenada. Há dois eixos principais: (A) um vertical, ditado por um grande elemento azul que se destaca à direita do eixo central da composição na página dupla, e (B) um eixo horizontal, formado por conjuntos de objetos azuis na base da composição, em uma sequência horizontal que atravessa toda a área disponível ao infográfico. Há, ainda, agrupamentos secundários, tais como (C) um arco, formado por objetos azuis logo abaixo do título, e (D) um grupo de conjuntos alinhados na horizontal. Poucos blocos de texto com destaques maiores em tons de azul podem ser identificados. Ao longo das páginas, há pequenas fotografias que se conectam por meio de linhas a outros elementos gráficos.

\subsection{Análise dos atributos visuais}

O atributo da cor de matiz azul predomina a composição sobre o branco da página dupla. $\mathrm{O}$ azul identifica os recipientes que representam o volume de água. $\mathrm{A}$ presença dessa cor pela página ressalta a ideia de "grande volume de água" e é intensificado em função do contraste com o fundo branco, que realça os contornos, melhorando a identificação dos agrupamentos. A associação com o elemento água é evidente, também, por ser uma cor característica das caixas-d'água no país. As garrafas, os galões e as caixas-d'água são representados tridimensionalmente, com o intuito de reforçar, ainda mais, a ideia de volume. A perspectiva forçada da torre central, com orientação vertical, em comparação ao automóvel, também exacerba a intenção de quantificar a água desperdiçada. Há o uso de transparência nas garrafas e galões, tanto com o objetivo de se assemelhar aos galões e garrafas plásticas transparentes existentes no mercado, quanto para reforçar o conceito de água potável, limpa, que está sendo descartada. A cor cinza é usada como atributo de cor - 
saturação neutra, tanto nos gráficos do tipo pizza, quanto no fundo dos círculos que acompanham as fotografias dos itens.

Linhas são empregadas como atributo topológico, estabelecendo conexões entre os elementos; elas ajudam a constituir agrupamentos com objetos que não estão próximos ou não possuem atributos visuais similares que os identifiquem como parte de um mesmo grupo na composição.

O atributo visual do tamanho é usado como recurso para comparar os itens em seu tamanho original ao lado dos volumes que representam a água. Por exemplo, o tamanho reduzido do saco de açúcar ao lado dos galões de água e da caixa-d'água, intensifica o contraste, aguçando a sensação de que algo muito pequeno gerou um gasto muito grande. Versões ampliadas do mesmo objeto são apresentadas um pouco acima do conjunto, conectadas por uma linha, com a finalidade de permitir a visualização do item com mais definição (por exemplo, a laranja é exibida em formato maior logo acima do conjunto).

Como forma de estabelecer uma integração dos elementos que fazem parte do infográfico, os itens fotográficos possuem a forma de um círculo como elemento de integração, que pode delimitar a imagem ou servir de fundo. Esse recurso faz com que um grupo heterogêneo de imagens possa ter algum tipo de similaridade, auxiliando a unidade da composição.

\subsection{Análise retórica}

Para que o objetivo da mensagem funcione, o orador pressupõe haver um conhecimento prévio do assunto por parte do auditório; nesse caso, o jornalista inicia a matéria argumentando que o leitor, como cidadão brasileiro, consome uma grande quantidade de água e tem conhecimento desse fato. $O$ orador presume que o leitor saiba que gasta muita água, mas que não tenha noção do grande volume demonstrado pela pesquisa que forneceu dados para que a matéria fosse realizada. $O$ fato e a presunção constituem o acordo sobre o real estabelecido entre o jornalista e o leitor. $A$ demonstração de que o volume é muito superior ao que se imagina instiga o auditório a fazer o seguinte julgamento de valor: seria correto gastar tanta água, enquanto 900 milhões de pessoas no mundo têm acesso restrito a ela (dado presente no texto verbal logo abaixo do título)? Esse julgamento corresponde ao acordo sobre o preferível, onde o leitor se solidariza com os que possuem pouco acesso a água e imagina ser melhor não desperdiçar tanto de forma a colaborar com a sociedade.

O infográfico reforça a presença do volume de água representando-a através de caixas-d'água, objeto que presume ser de conhecimento do leitor e que indique um grande volume de líquido. Ou seja, a escolha feita pelo orador foi representar a água, substituindo-a por um objeto que represente seu volume, havendo ainda galões e garrafas representando volumes menores. Nesse caso, nota-se a figura retórica da metonímia, dado que a água precisa ser armazenada em um recipiente, para que esteja disponível para o consumo em nossas residências. Apesar de não ser o único modo de armazenagem, a caixa-d'água tem uma relação causal com a água.

O empilhamento de caixas-d'água em torres, principalmente a torre central, que ocupa boa parte da composição, configura o efeito retórico da hipérbole, reforçando a presença do imenso volume de água despendido no setor industrial. $A$ 
figura de repetição também se apresenta no infográfico, de modo a ampliar a impressão do consumo com diversos exemplos similares (quanto gastam alimentos, indústria, objetos) e com muitas unidades de garrafas, galões e caixas-d'água distribuídos em grupos pela composição, mantendo a presença do assunto na consciência do leitor. Há, também, a figura da divisão, tendo em vista o infográfico distribuir em grupos o total de água gasto, reforçando ainda mais a presença no argumento.

Já a palavra destacada no título, "nossa", faz com que a participação do leitor se intensifique; ela permite uma maior identificação com a mensagem e reforça o efeito de comunhão. As imagens que representam atividades ou produtos também reforçam a identificação do leitor com o discurso, dado que se presume que todos tenham necessidades básicas representadas pelos grupos nutrição e higiene, tais como escovar os dentes, tomar banho, consumir açúcar e pão ou usar calças jeans.

O discurso se constrói basicamente no argumento quase-lógico da comparação, para levar o auditório a tomar consciência do seu consumo. Ao associar atividades do cotidiano e produtos de necessidade básica, além da indústria, o leitor passa a ter noção das quantidades envolvidas em cada um desses itens, facilitando a percepção de quantos litros de água são efetivamente gastos por cada indivíduo.

À direita, um diagrama com o planeta e imagens que representam as consequências que o consumo desenfreado de água pode causar reforçam a questão dos valores intrínsecos a um bom cidadão, levando o leitor a não desejar colaborar com a destruição do planeta. A escolha da inserção dessa pequena composição visual próxima à área onde a leitura se encerra, na direita, acima das últimas colunas de caixas-d'água, reforça a presença das consequências de se manter esse comportamento, indicando a necessidade de uma mudança de hábitos da sociedade como um todo. O que seria mais um acordo sobre o preferível da argumentação proposta pelo infográfico do jornal.

\subsection{Considerações sobre o caso exemplar}

Apesar da composição parecer um tanto poluída, essa aparente desorganização ressalta ainda mais a ideia do grande volume que o leitor desconhece desperdiçar, principalmente pela presença da pilha central volumosa de caixas-d'água em comparação ao automóvel. O infográfico, mesmo com pouco texto descritivo, consegue transmitir a ideia da necessidade de mudança em relação ao consumo de água no planeta, estabelecendo uma identificação do leitor como indivíduo também responsável pelo futuro do planeta.

\section{CONCLUSÃO}

O foco deste artigo esteve na identificação de dispositivos retóricos atuantes no discurso visual dos infográficos, a partir da apresentação de um caso exemplar. As considerações apresentadas sinalizam para a necessidade de os designers de informação terem maior domínio sobre as ferramentas possíveis de serem usadas no momento da elaboração de gráficos e infográficos. Destaca-se que o referencial teórico adotado (relacionado às questões da linguagem, da percepção visual e da retórica) mostra-se relevante ao campo do Design, uma vez que fornece subsídios para uma maior compreensão sobre o funcionamento do "auditório" - tanto no primeiro 
momento, na aquisição de estímulos, quanto em uma segunda etapa, na cognição propriamente dita, e, finalmente, na interpretação das informações.

Assim, espera-se que o estudo aqui apresentado seja útil à comunidade acadêmica e ao meio profissional, apresentando caminhos para que seja possível compreender o funcionamento dos processos que influenciam o poder persuasivo dos infográficos, observando-se como se dão a percepção, cognição e a interpretação dos mesmos pelo leitor.

\section{REFERÊNCIAS}

[Gráfico]. Tese (Doutorado em Design). Departamento de Artes. Pontifícia Universidade Católica. Rio de Janeiro, 2009.

ALMEIDA JUNIOR, Licínio Nascimento; NOJIMA, Vera Lúcia Retórica do design gráfico: da prática a teoria. São Paulo: Blucher, 2010.

BERTIN, Jacques. Semiology of graphics, Wisconsin: University of Wisconsin Press, 1983.

BONSIEPE, Gui. Design, cultura e sociedade. São Paulo: Blucher, 2011.

CAIRO, Alberto. Infografía $\mathbf{2 . 0}$ visualización interactiva de información en prensa. Madrid: Alamut, 2008.

FEW, Stephen. Now you see it. Oakland: Analitics Press, 2009.

INFOLIDE. 6ạ Mostra de infografia. São Paulo: Infolide, 2012.

KRISTEVA, Julia. História da linguagem. Portugal: Edições 70, 1974.

LIMA, Ricardo Cunha. Análise da infografia jornalística. Dissertação (Mestrado em Design). ESDI/UERJ. Rio de Janeiro, 2009.

MÓDOLO, Cristiane Machado. Infográficos na mídia impressa: um estudo semiótico na revista Mundo Estranho. Dissertação (Mestrado em Comunicação). Universidade Estadual Paulista. Bauru, 2008.

NEURATH, Otto. International picture language. The Department of Typography \& Graphic Communication. Reading: University of Reading Press, 1980.

NOGUEIRA, Daniel Moura. Visualização de dados: o discurso persuasivo dos atributos visuais nos infográficos. Dissertação (mestrado) - Pontifícia Universidade Católica do Rio de Janeiro, Departamento de Artes e Design. Rio de Janeiro, 2014.

PERELMAN, Chaim; OLBRECHTS-TYTECA, Lucie. Tratado da argumentação: a Nova Retórica, São Paulo: Martins Fontes, 2005.

SOUZA LEITE, João. O discurso do design gráfico como polifonia. Estudos em Design, v. 5, n. 1. pp. 59-68. Rio de Janeiro: AEND-BR, 1997.

TREISMANN, Anne; GORMICAN, Stephen. Feature analisys in early vision: evidence from search asymmetries. Psychological Review, v.95, n.1, pp.15-48, jan. 1988.

WARE, Colin. Information visualization: perception for design. San Francisco: MK, 2004. 
Visual thinking for design. São Francisco: MK, 2008.

WILDBUR, Peter; BURKE, Michael. Information graphics: innovative solutions in contemporary design. London: Thames \& Hudson, 1998. 